\title{
Left ventricular performance in alcoholic patients without chronic liver disease
}

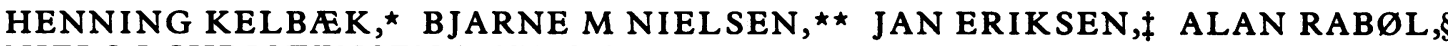 \\ NIELS J CHRISTENSEN, $\dagger$ JENS O LUND,§ OLAF BONNEVIE, $\ddagger$ OLE MUNCK, \\ JOHN GODTFREDSENT \\ From the Department of Clinical Physiology and Nuclear Medicine, ${ }^{\star}$ Department of Internal Medicine and \\ Endocrinology $\dagger$ and Department of Cardiology, $₫$ Herlev Hospital, Herlev; Department of Psychiatry, $\star \star$ \\ Department of Clinical Physiology and Nuclear Medicine,§ and Department of Internal Medicine and \\ Gastroenterology, $\ddagger$ Frederiksberg Hospital, Frederiksberg, Denmark
}

SUMMARY Left ventricular performance was studied non-invasively in 24 chronic alcoholics without liver disease. Twelve patients who had abstained from drinking for at least one month (group A) and 12 sex and age matched patients who had ceased drinking during the preceding 24 hours (group B) were studied at rest and during 50\% submaximal exercise. Cardiac output and stroke volume were measured by first passage and left ventricular ejection fraction by multigated radionuclide cardiography. Twelve healthy sex and age matched controls were also studied. Haemodynamic variables were similar in group A and the controls, except that in group A left ventricular end systolic volume index did not decrease during exercise. In group B the heart rate was increased both at rest and during exercise and plasma noradrenaline concentrations were increased. The stroke volume index did not increase significantly during exercise in group B. In addition, the increase in left ventricular ejection fraction was smaller in group B than in controls End systolic contraction was reduced in group B patients and diastolic blood pressure was increased.

These results suggest that cardiac abnormalities in chronic alcoholics may be reversed after cessation of drinking if no chronic liver disease is present. Recent alcohol consumption increases sympathetic nervous activity, impairs cardiac contractility, and increases afterload during physical stress.

Preclinical cardiomyopathy is frequently found in chronic alcoholics. ${ }^{1-5}$ We have recently reported that determination of the left ventricular ejection fraction at rest and during exercise by radionuclide cardiography may be useful in the detection of subclinical cardiomyopathy in patients with alcoholic cirrhosis. ${ }^{6}$ There was a slightly increased left atrial dimension but no significant alterations of systolic time intervals and echocardiographic variables at rest in cirrhotic patients who had ceased drinking

Requests for reprints to Dr Henning Kelbæk, Department of Clinical Physiology and Nuclear Medicine, Herlev Hospital, University of Copenhagen, DK-2730 Herlev, Denmark.

Accepted for publication 15 May 1987 compared with controls. ${ }^{6}$ These findings indicated that at least some of the previously reported changes of cardiac function in chronic alcoholics ${ }^{3-57^{-9}}$ may be attributed to the influence of recent acute intoxi- $\tilde{O}$ cation. This concept is supported by the study of Reeves $e t$ al, who found no echocardiographic evidence of cardiac dysfunction in alcoholics after prolonged abstinence. ${ }^{10}$ In addition, the importance of chronic liver damage in the evolution of alcoholic $\stackrel{\varrho}{C}$ cardiomyopathy has been a matter of debate, ${ }^{11} 12$ the prevailing view being that overt cardiomyopathy is infrequent in cirrhotic patients.

The present study was undertaken $(a)$ to characterise left ventricular function at rest and during exercise in chronic alcoholics without ehronic liver disease, and $(b)$ to evaluate the influence of recent 
Table 1 Characteristics of patients and control subjects (medians with ranges in parentheses)

\begin{tabular}{llll}
\hline & Group A & Group B & Controls \\
\hline Age (years) & 44 & 42 & 43 \\
& $(37-59)$ & $(28-63)$ & $(30-56)$ \\
Sex (M/F) & $9 / 3$ & $9 / 3$ & $9 / 3$ \\
Weight (kg) & 69 & 67 & $76^{\star}$ \\
& $(54-78)$ & $(49-86)$ & $(64-99)$ \\
Height (m) & 1.73 & 1.73 & 1.79 \\
Body surface & $(1.65-1 \cdot 80)$ & $(1.59-1 \cdot 80)$ & $(1.66-1 \cdot 82)$ \\
$\left(\mathrm{m}^{2}\right)$ & $(1.61-1.98)$ & $(1.80$ & $1.94^{\star}$ \\
\end{tabular}

${ }^{\star} \mathrm{p}<0.05$ vs patient groups.

alcohol intake on left ventricular function in a similar group of patients.

\section{Patients and methods}

\section{PATIENTS}

All subjects gave their informed consent to the study, which was approved by the local ethics committee. We studied 24 patients attending the alcohol clinic of Frederiksberg Hospital. Exclusion criteria were evidence of chronic liver disease, cardiac disease (congenital, rheumatic, and ischaemic heart disease; cor pulmonale; and atrial fibrillation), hypertension, diabetes mellitus, anaemia, and endocrinological disorders. All patients had had a chronic alcohol intake of at least $100 \mathrm{~g}$ daily. Twelve patients (group A) with a history of 6-30 years (median 15 years) had abstained for a median period of 2 months (range 1-11). Twelve carefully matched patients (group B) with a history of 7-30 years (median 13 years) of alcoholism and abuse within the past 7 to 45 days (median 15 days) were investigated within 24 hours of their serum ethanol concentration falling to zero. All patients had started medical treatment with disulfiram, an abstention-supporting drug. Ten out of 12 patients in group $B$ had received diazepam, an anxiolytic drug, to relieve symptoms of abstinence during the preceding 24 hours. In a few patients an additional dose of 5 or $10 \mathrm{mg}$ was admin- istered at least an hour before the haemodynamic investigation. Table 1 outlines patient characteristics and data from the sex and aged matched control group.

\section{STUDY PROTOCOL}

Venous blood samples were drawn for biochemical liver function tests and to rule out the presence of ethanol in serum. In patients with abnormal biochemical data the tests were repeated two weeks later to rule out chronic liver disease.

A bicycle exercise test was performed to determine the $50 \%$ submaximal work capacity of the subjects.

Radionuclide cardiography was performed with the patient upright at rest and during submaximal exercise corresponding to $50 \%$ of the maximal work capacity as determined by the exercise test. Autologous red blood cells were labelled in vitro with technetium- $99 \mathrm{~m}$ as previously described. ${ }^{13}$ Cardiac output was determined by the first passage radionuclide technique. ${ }^{14} \mathrm{~A}$ bolus of approximately 14 $\mathrm{mCi}(518 \mathrm{MBq})$ was injected into the right basilic vein and flushed with $20 \mathrm{ml}$ of saline. The bolus passage was registered with a Siemens ZLC cardiac gamma camera equipped with a low energy all purpose parallel hole collimator in the left anterior oblique position with a 5 to $10^{\circ}$ caudal tilt over the precordium. The first passage and equilibrium data were acquired by connecting the gamma camera to a Scintiview II nuclear medicine computer (Siemens). Stroke volume was determined as cardiac output divided by heart rate. The left ventricular ejection fraction was determined by multiple electrocardiogram-gated cardiography as described in detail elsewhere. ${ }^{6}$ Left ventricular end diastolic volume was determined as stroke volume divided by left ventricular ejection fraction, and left ventricular end systolic volume as left ventricular end diastolic volume minus stroke volume.

Ascultatory blood pressure, heart rate, and plasma catecholamine concentrations were recorded during

Table 2 Heart rate and blood pressure at rest and at submaximal workloads (medians with ranges in parentheses)

\begin{tabular}{|c|c|c|c|c|c|c|}
\hline & \multicolumn{2}{|l|}{ Group $A$} & \multicolumn{2}{|l|}{ Group B } & \multicolumn{2}{|l|}{ Controls } \\
\hline & Rest & Exercise & Rest & Exercise & Rest & Exercise \\
\hline Workload (W) & - & $\begin{array}{l}75 \\
(65-100)\end{array}$ & - & $\begin{array}{l}50^{\star} \\
(25-85)\end{array}$ & - & $\begin{array}{l}90 \\
(60-140)\end{array}$ \\
\hline Heart rate (beats/min) & 78 & 122 & $100^{\star}$ & $135^{\star}$ & 85 & 120 \\
\hline Systolic BP (mm Hg) & $\begin{array}{l}(62-100) \\
120\end{array}$ & $\begin{array}{l}(100-140) \\
150\end{array}$ & $\begin{array}{l}(70-130) \\
135\end{array}$ & $\begin{array}{l}(120-145) \\
165\end{array}$ & $\begin{array}{l}(63-100) \\
125\end{array}$ & $\begin{array}{l}(95-133) \\
170\end{array}$ \\
\hline & $(110-140)$ & $(130-170)$ & $(105-180)$ & $(130-195)$ & $(110-145)$ & $(120-205)$ \\
\hline Diastolic BP (mm Hg) & $\begin{array}{l}85 \\
(60-90)\end{array}$ & $\begin{array}{l}85 \\
(75-100)\end{array}$ & $\begin{array}{l}90 \\
(80-110)\end{array}$ & $\begin{array}{l}105 \dagger \\
(85-115)\end{array}$ & $\begin{array}{l}85 \\
(75-95)\end{array}$ & $\begin{array}{l}90 \\
(70-105)\end{array}$ \\
\hline
\end{tabular}

${ }^{\star} \mathrm{p}<0.05$ vs other groups. $\dagger \mathrm{p}<0.05$ vs rest. BP, blood pressure. 

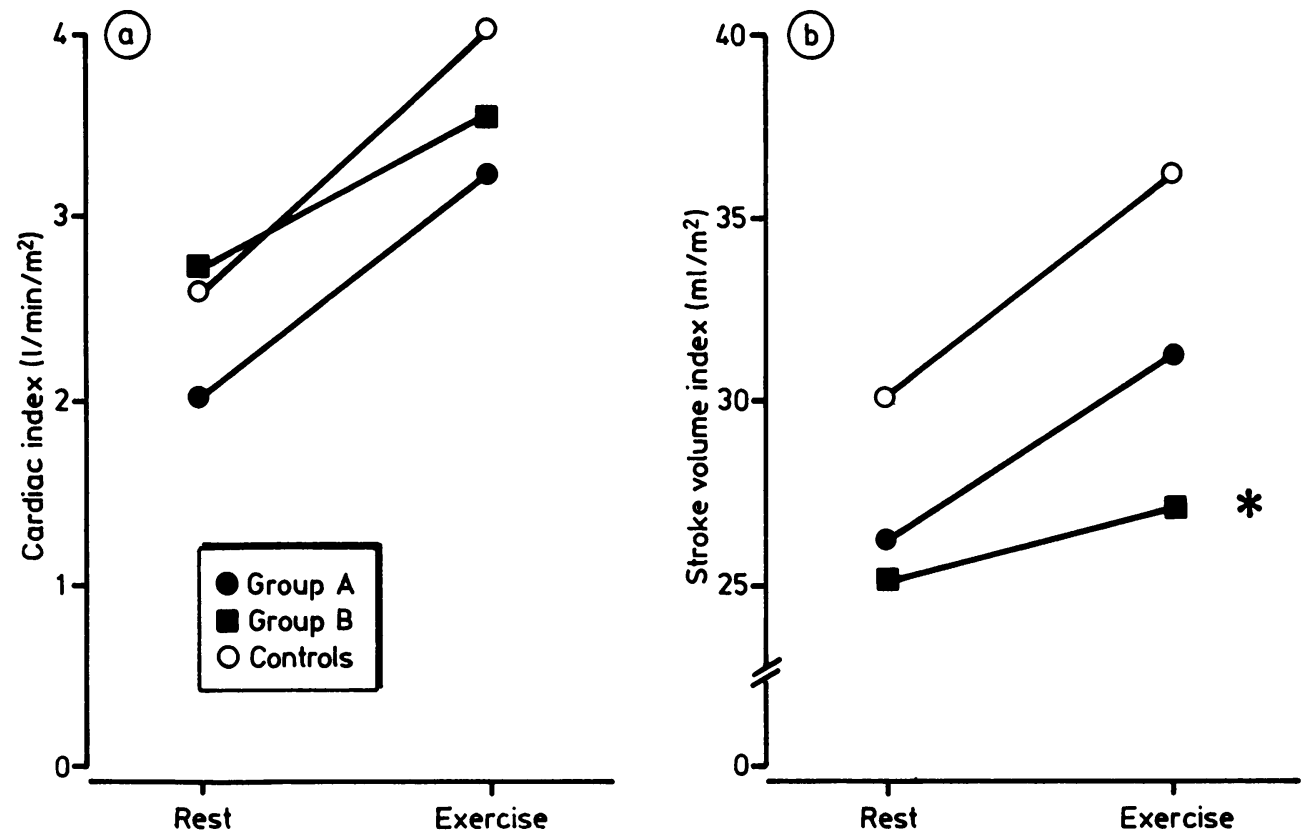

Fig 1 Median values of (a) cardiac index and (b) stroke volume index at rest and during exercise in group $A$, group $B$, and controls. ${ }^{\star} p<0.05$ vs controls.

the radionuclide data acquisitions. Plasma adrenaline and noradrenaline were measured by a singleisotope derivative assay. ${ }^{15} 16$

Data analyses were carried out by observers who were not aware of the group to which the patient belonged.

\section{STATISTICAL ANALYSIS}

Statistical analyses were carried out by the rank sum tests for paired (Pratt) and unpaired observations (Mann-Whitney). The results were expressed as median values and ranges. A p value $<0.05$ was considered significant.

\section{Results}

The $50 \%$ submaximal workload in group $\mathbf{A}$ did not differ significantly from that in the control subjects, whereas the workload in group B was significantly reduced $(p<0.05)$ (table 2$)$. Heart rate was increased in group B both at rest and during exercise $(\mathrm{p}<0.05)$, but the heart rate changes in response to exercise were of the same magnitude in the three groups. There was an abnormal rise in diastolic blood pressure during exercise in group B (table 2).

Cardiac index tended to be lower in group $A$ than in the controls $(0.05<p<0.10)$. There were no significant differences between stroke volume index
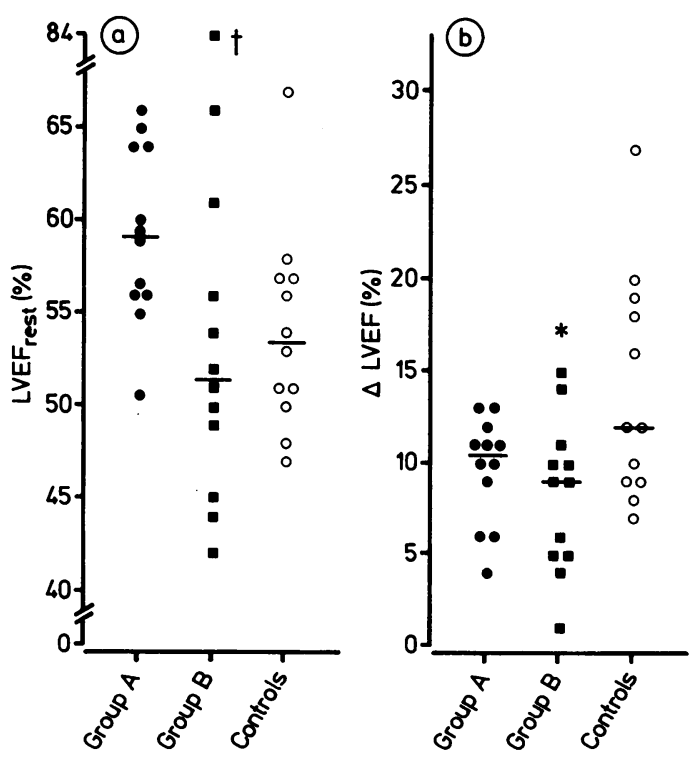

Fig 2 (a) Left ventricular ejection fraction at rest $\left(L V E F_{\text {rest }}\right)$ and $(b)$ the increase in $L V E F$ during exercise $(\triangle L V E F)$. Bars are median values. $\dagger p<0.05$ vs group $A$ $\star_{p}<0.05$ vs controls. 


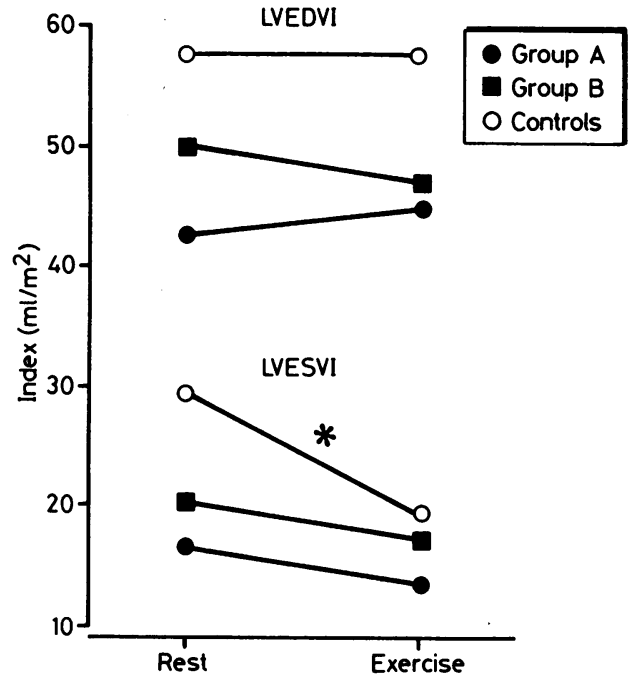

Fig 3 Median values of left ventricular end diastolic volume index (LVEDVI) and left ventricular end systolic volume index (LVESVI) at rest and during exercise. ${ }^{\star} p<0.05$ vs patient groups.

at rest in the three groups. During exercise, however, stroke volume index was significantly lower in group B (median $27 \mathrm{ml} / \mathrm{m}^{2}$ ) than in the controls (median $36 \mathrm{ml} / \mathrm{m}^{2}$ ), $\mathrm{p}<0.05$ (fig 1 ).

There was a wide range of results for left ventricular ejection fraction in groups A and B (fig 2). Left ventricular ejection fraction at rest was higher in group A than in group B $(p<0.05)$. The increase in left ventricular ejection fraction from rest to exercise was $9 \%$ in group $\mathbf{B}$ and $12 \%$ in the controls ( $<0.05$ ) (fig 2).

Figure 3 shows the left ventricular volumes in the three groups. The left ventricular end diastolic volume index at rest was slightly lower in group $A$ than in the controls, but this difference did not reach statistical significance $(0.05<p<0.10)$. There were no significant changes in end diastolic volume from rest to exercise in any of the groups. The left ventricular end systolic volume index fell significantly in the controls but not in either group A or B (fig 3).
Plasma adrenaline concentrations at rest were similar in the three groups, and the increases in response to exercise were of the same magnitude (table 3). Plasma noradrenaline concentrations were not significantly different in group $A$ and controls. In group B, however, plasma noradrenaline at rest was significantly higher than in group $A$ or the controls $(p<0.05)$. During exercise plasma noradrenaline concentrations were higher in group $B$ than in group A (table 3).

\section{Discussion}

In the present study we measured central haemodynamic variables at rest and during submaximal exercise in patients with chronic alcohol abuse. Only seven patients had a history of alcohol abuse of $<10$ years. In patients who had abstained from drinking for at least a month (group A) only three patients had an increase in left ventricular ejection fraction during exercise of $<7 \%$, suggesting that cardiac contractility was preserved in most patients of this group. In a previous study of patients with a comparable alcohol history we found left ventricular ejection fraction abnormalities in 12 out of 15 patients. ${ }^{6}$ None of these patients were abusing alcohol at the time of investigation but all had biopsyconfirmed alcoholic cirrhosis. Comparison with the present results suggests that the development of chronic liver damage may have a role in the pathogenesis of alcoholic cardiomyopathy. This concept is supported by reports of severe cardiac failure developing in patients with alcoholic cirrhosis. ${ }^{17}$ In another study it was reported that most of the hepatic changes found at necropsy of patients with alcoholic cardiomyopathy could be related to effects of acute and chronic congestive heart failure. ${ }^{11}$ Ahmed et al evaluated cardiac haemodynamic function in alcoholic patients with and without cirrhosis and found that although overt cardiomyopathy was infrequent in cirrhotic patients, asymptomatic myocardial disease might become clinically important during volume or pressure overload. ${ }^{12}$

In our study the left ventricular end systolic volume index failed to decrease significantly during ex-

Table 3 Plasma catecholamine concentrations at rest and during exercise (medians with ranges in parentheses)

\begin{tabular}{|c|c|c|c|c|c|c|}
\hline & \multicolumn{2}{|l|}{ Group $A$} & \multicolumn{2}{|l|}{ Group B } & \multicolumn{2}{|l|}{ Controls } \\
\hline & $\overline{\text { Rest }}$ & Exercise & Rest & Exercise & Rest & Exercise \\
\hline $\begin{array}{l}\text { Adrenaline }(\mathrm{ng} / \mathrm{ml}) \\
\text { Noradrenaline }(\mathrm{ng} / \mathrm{ml})\end{array}$ & $\begin{array}{l}0.04 \\
(0.02-0.20) \\
0.51 \\
(0.42-1 \cdot 14)\end{array}$ & $\begin{array}{l}0.09 \\
(0.04-0.38) \\
0 \cdot 72 \\
(0 \cdot 46-1 \cdot 17)\end{array}$ & $\begin{array}{l}0.04 \\
(0.00-0.07) \\
0.74^{\star} \\
(0.54-1.72)\end{array}$ & $\begin{array}{l}0.10 \\
(0.03-0 \cdot 15) \\
1.07 \dagger \\
(0.62-2 \cdot 14)\end{array}$ & $\begin{array}{l}0.05 \\
(0.01-0.10) \\
0.55 \\
(0.26-1.09)\end{array}$ & $\begin{array}{l}0.10 \\
(0.03-0.18) \\
0.91 \\
(0.64-1 \cdot 77)\end{array}$ \\
\hline
\end{tabular}

${ }^{\star} \mathrm{p}<0.05$ vs other groups. $\dagger \mathrm{p}<0.05$ vs group A. Conversion: traditional units to. I-adrenaline: $1 \mathrm{ng} / \mathrm{ml}=5.46 \mathrm{nmol} / \mathrm{l} ;$ noradrenaline: $1 \mathrm{ng} / \mathrm{ml}=5.91 \mathrm{nmol} / \mathrm{l}$. 
ercise in both patient groups. In the face of a mean arterial blood pressure that was not higher than that in the control subjects, this result may be taken to indicate a reduction in cardiac contractility during physical stress, even in alcoholic patients without chronic liver disease.

The acute effects of alcohol intoxication on left ventricular performance have been thoroughly investigated in healthy subjects not consuming alcohol each day. ${ }^{18-24}$ The results of these studies are conflicting, although the prevailing view is that intoxication depresses myocardial contractility. In two recent controlled non-invasive studies acute alcohol intoxication reduced stroke volume ${ }^{25}$ and left ventricular ejection fraction. ${ }^{26}$ In a study of cardiac performance in the hangover phase of acute alcohol intoxication heart rate, left ventricular ejection fraction, and cardiac output were increased. ${ }^{27}$ Thus acute and recent intoxication would be expected to influence the results of haemodynamic investigations. Whereas patients of group $A$ in our study were investigated at least one month after alcohol abstention, group B patients were examined within 24 hours after an alcohol excess. The two patient groups were matched in all respects except their drinking habit. Thus the differences in haemodynamic variables between group $\mathbf{B}$ and group $\mathbf{A}$ may be attributed entirely to recent alcohol intoxication in group B. Despite the reduced physical work capacity in group B, the workload applied to these patients was sufficient to produce an increase in heart rate similar to that in the other two study groups. Heart rate was increased both at rest and during exercise in group $B$, but otherwise there were no other haemodynamic alterations to indicate an increase in left ventricular performance. On the contrary, the lower left ventricular ejection fraction at rest, the small and insignificant increase in stroke volume from rest to exercise together with a reduced increase in left ventricular ejection fraction, and an insignificant decrease in left ventricular end systolic volume index suggest that cardiac contractility was impaired in alcoholic patients early after cessation of alcohol intake. The role of alcohol-induced hypertension in the development of alcoholic cardiomyopathy has been emphasised. ${ }^{28}$ None of our patients had hypertension, but we cannot exclude the possibility that the abnormal rise in diastolic blood pressure during exercise in group B patients, which increased the afterload, may have contributed to the reduced left ventricular performance. ${ }^{29}$

Plasma catecholamine concentrations in group A did not differ from those in the control subjects, and no alterations were found in the plasma adrenaline concentrations in any of the patient groups. The increased plasma noradrenaline concentrations in group B were probably a result of the recent intoxication. ${ }^{30}$ An increase in sympathetic nervous activity was also reflected by the increased heart rate. The concomitant increase in left ventricular performance in the early alcohol withdrawal phase described previously, ${ }^{27}$ and recently supported by a study of healthy volunteers in our laboratory (unpublished data), however, could not be demonstrated in the alcoholic patients.

We examined left ventricular performance at rest and during $50 \%$ submaximal exercise in chronic alcoholics without liver disease. We found a reduced end systolic contraction during exercise in patients who had abstained from drinking for at least a month. In patients who had ceased drinking only within the past 24 hours sympathetic nervous activity was increased. Physical work capacity was reduced and left ventricular performance in response to exercise was abnormal. A reduced increase in stroke volume index and left ventricular ejection fraction reflected an impaired left ventricular contractility in the face of an increased afterload and despite an increase in sympathetic tone. Most of the changes in cardiac function in these patients will not be disclosed unless they are exposed to physical stress.

This work was supported by the Danish Medical Research Council, the Danish Heart Foundation, Novo's Foundation, and the Foundation of Ebba Celinder.

\section{References}

1 Gould L, Shariff M, Zahir M, Dilieto M. Cardiac hemodynamics in alcoholic patients with chronic liver disease and a presystolic gallop. J Clin Invest 1969;48:860-8.

2 Zambrano SS, Mazzotta JF, Sherman D, Spodick DH. Cardiac dysfunction in unselected chronic alcoholic patients: noninvasive screening by systolic time intervals. Am Heart $J$ 1974;87:318-20.

3 Mathews EC, Gardin JM, Henry WL, et al. Echocardiographic abnormalities in chronic alcoholics with and without overt congestive heart failure. $\mathrm{Am} \mathrm{J}$ Cardiol 1981;47:570-8.

4 Kino M, Imamitchi $H$, Morigutchi $M$, Kawamura $K$, Takatsu T. Cardiovascular status in asymptomatic alcoholics, with reference to the level of ethanol consumption. Br Heart $J$ 1981;46:545-51.

5 Dancy M, Bland JM, Leech G, Gaitonde MK, Maxwell JD. Preclinical left ventricular abnormalities in alcoholics are independent of nutritional status, cirrhosis, and cigarette smoking. Lancet 1985;i:1122-5.

6 Kelbæk H, Eriksen J, Brynjolf I, et al. Cardiac performance in patients with asymptomatic alcoholic cirrhosis of the liver. Am J Cardiol 1984;54:852-5.

7 Spodick DH, Pigott WM, Chirife R. Preclinical cardiac 
malfunction in chronic alcoholism. $N$ Engl $J$ Med 1972;287:677-80.

8 Levi GF, Quadri A, Ratti S, Basagni M. Preclinical abnormality of left ventricular function in chronic alcoholics. Br Heart J 1977;39:35-7.

9 Askanas A, Udoshi M, Sadjadi SA. The heart in chronic alcoholism: a noninvasive study. Am Heart $J$ 1980;99:9-16.

10 Reeves WC, Nanda NC, Gramiah R. Echocardiography in chronic alcoholics following prolonged periods of abstinence. Am Heart $J$ 1978;95:578-83.

11 Lefkowitch JH, Fenoglio JJ. Liver disease in alcoholic cardiomyopathy: evidence against cirrhosis. Hum Pathol 1983;14:457-63.

12 Ahmed SS, Howard M, tenHove W, Leevy CM, Regan TJ. Cardiac function in alcoholics with cirrhosis: absence of overt cardiomyopathy-myth or fact? $\mathrm{J} \mathrm{Am}$ Coll Cardiol 1984;3:696-702.

13 Kelbæk H, Gjørup T, Fogh J. In vivo stability of in vitro labelled ${ }^{99 \mathrm{~m}}$ Tc-red blood cells. $\mathrm{Nucl} \mathrm{Med}$ Commun 1986;7:541-7.

14 Kelbæk H, Hartling OJ, Skagen K, Munck O, Henriksen $\mathrm{O}$, Godtfredsen J. First passage radionuclide determination of cardiac output: an improved gamma camera method. $J$ Nucl Med (in press).

15 Christensen NJ, Vestergaard P, Sørensen T, Rafaelsen OJ. Cerebrospinal fluid adrenaline and noradrenaline in depressed patients. Acta Psychiatr Scand 1980;61:178-82.

16 Kelbæk H, Gjørup T, Christensen NJ, Vestergaard B, Godtfredsen J. Cardiac function and plasma catecholamines during upright exercise in healthy young subjects. Int J Cardiol 1986;10:223-31.

17 Kelbæk H, Bødker B, Godtfredsen J. Congestive alcoholic cardiomyopathy. Ugeskr Laeger 1985; 147:3472-4.

18 Regan TJ, Koroxenidis G, Moschos CB, Oldewurtel HA, Lenan PH, Hellems HK. The acute metabolic and hemodynamic responses of the left ventricle to ethanol. J Clin Invest 1966;45:270-80.
19 Riff DP, Jain AC, Doyle JT. Acute hemodynamic effects of ethanol on normal human volunteers. Am Heart J 1969;78:592-7.

20 Blomqvist G, Saltin B, Mitchell JH. Acute effects of ethanol ingestion on the response to submaximal and maximal exercise in man. Circulation 1970;42:463-70.

21 Newman WH, Valicenti JF. Ventricular function following acute alcohol administration: a strain-gauge analysis of depressed ventricular dynamics. $\mathrm{Am}$ Heart J 1971;81:61-8.

22 Ahmed SS, Levinson GE, Regan TJ. Depression of myocardial contractility with low doses of ethanol in normal man. Circulation 1973;48:378-85.

23 Horwitz LD, Atkins JM. Acute effects of ethanol on left ventricular performance. Circulation 1974; 49:124-8.

24 Delgado CE, Fortuin NJ, Ross RS. Acute effects of low doses of alcohol on left ventricular function by echocardiography. Circulation 1975;51:535-40.

25 Kupari M. Acute cardiovascular effects of ethanol. A controlled non-invasive study. $\mathrm{Br}$ Heart $J$ 1983;49:174-82.

26 Kelbæk H, Gjørup T, Brynjolf I, Christensen NJ, Godtfredsen J, Vestergaard B. Acute effects of alcohol on left ventricular function in healthy subjects at rest and during upright exercise. $A m J$ Cardiol 1985;55:164-7.

27 Kupari M. Drunkenness, hangover, and the heart. Acta Med Scand 1983;213:84-90.

28 Friedman HS, Vasavada BC, Malec AM, Hasson KK, Shah A, Siddiqui S. Cardiac function in alcoholassociated systemic hypertension. Am J Cardiol 1986;57:227-31.

29 Lang RM, Borow KM, Neumann A, Feldman T. Adverse cardiac effects of acute alcohol ingestion in young adults. Ann Intern Med 1985;102:742-7.

30 Eisenhofer G, Lambie DG, Johnson RH. Effects of ethanol on plasma catecholamines and norepinephrine clearance. Clin Pharmacol Ther 1983;34:143-7. 